\title{
Euphornin reduces proliferation of human cervical adenocarcinoma HeLa cells through induction of apoptosis and G2/M cell cycle arrest
}

This article was published in the following Dove Press journal:

OncoTargets and Therapy

\section{Xiao-Qiang $\mathrm{Li}^{1, *}$ \\ Yin-Liang Bail,* \\ De-Li Zhangl,* \\ Hai-Sheng Jiao' \\ Rong-Xia $\mathrm{He}^{2}$}

'Pharmacy Department, Lanzhou University Second Hospital, Lanzhou 730030, China;

${ }^{2}$ Department of Gynecology, Lanzhou University Second Hospital, Lanzhou 730030, China

*These authors contributed equally to this work
Correspondence: Rong-Xia He Department of Gynecology, Lanzhou University Second Hospital, Cuiying Men Road 82, Lanzhou 730030, China

Tel +869318943051

Fax +869318463553

Email lzuhrx@I63.com
Background: The plant Euphorbia helioscopia L. has been used in traditional Chinese medicine for treating various disorders such as tuberculosis and edema. The aim of this study was to investigate the effect of euphornin, a bioactive compound isolated from E. helioscopia, on proliferation of human cervical adenocarcinoma HeLa cells by analyzing cell viability, rate of apoptosis, and cell cycle progression.

Materials and methods: The sulforhodamine B assay was used to study the effect of euphornin on the proliferation of HeLa cells. Morphological changes to cell nuclei were identified after Hoechst 33342 staining. Mitochondrial membrane depolarization (MMP) was analyzed after staining with JC-1 dye. The influence of euphornin on the apoptosis rate was analyzed by Annexin V/propidium iodide double staining. Fluorescence-activated cell sorting was applied to investigate the influence of euphornin on cell cycle progression. Proteins were obtained from HeLa cells and analyzed by Western blots.

Results: A cell viability assay showed that euphornin inhibited proliferation of HeLa cells in a dose-dependent and time-dependent manner. Euphornin also induced apoptosis in a concentration-dependent manner, with the rates of apoptosis ranging from $25.3 \%$ to $52.6 \%$. A high concentration of euphornin was found to block HeLa cells at the G2/M stage. A Western blot analysis suggested that euphornin might exhibit antitumor activity by inducing apoptosis. Euphornin treatment altered the ratio of Bax/Bcl-2 in HeLa cells, which led to the release of cytochrome complex. The levels of cleaved caspase-3, caspase- 8 , caspase- 9 , and caspase-10 were also markedly increased by euphornin treatment. Analysis of cell cycles indicated that euphornin induced cell cycle arrest by increasing the level of the phospho-CDK1 (Tyr15) protein. The various assays demonstrated that euphornin treatment resulted in a significant suppression of cell growth accompanied by G2/M cell cycle arrest and increased rate of apoptosis via mitochondrial and caspase pathways.

Conclusion: Our findings suggest that euphornin has the potential to be used as a cancer therapeutic agent against human cervical adenocarcinoma.

Keywords: euphornin, cervical adenocarcinoma HeLa cells, proliferation, apoptosis, G2/M cell cycle arrest

\section{Introduction}

Cervical carcinoma is the fourth most common cause of death from cancer in women worldwide and accounts for $\sim 12 \%$ of all cancers in women. In recent years, the rate of cervical cancer in young adults has increased, with a greater number of diagnoses in women aged between 35 and 55 years. ${ }^{1}$ Although the pathogenesis of cervical cancer is still obscure, infection with human papillomavirus appears to be a 


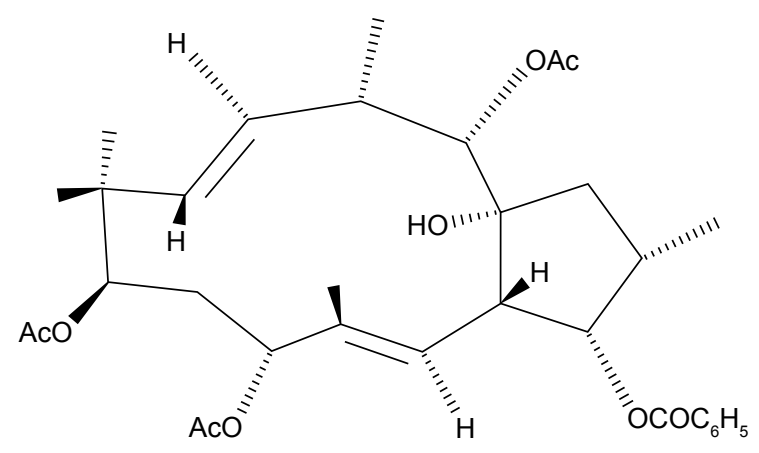

Figure I Structure of euphornin.

necessary factor in the development of almost all cases of cervical cancer., ${ }^{2,3}$ Early screening for cervical cancer has been shown to be important to its prevention and treatment. ${ }^{4}$ Although improvements in the diagnosis and prevention of the disease have occurred, the effectiveness of the available therapeutic regimens remains limited. In this regard, there has been a continuing search for the mechanisms underlying tumorigenesis in cervical cancer in order to identify novel therapeutic options. ${ }^{5}$

Apoptosis is a process of cell death that removes redundant cells and tissues to maintain homeostasis. ${ }^{6}$ With respect to tumor cells, apoptosis is regarded as a potent defense mechanism for cancer prevention and provides a therapeutic target against cancers. ${ }^{7}$ Various natural products have been reported to possess antitumor activities and show low side effects; these compounds can eliminate tumor cells by regulating apoptotic signaling. ${ }^{8-10}$

The plant Euphorbia helioscopia L. has been widely used for treating various disorders in China, such as tuberculosis and edema, and it has been suggested to have activity against cervical and esophageal cancers. ${ }^{11,12}$ Extracts from E. helioscopia have been shown to inhibit proliferation of human cancer cell lines. ${ }^{13}$ One of the main bioactive compounds isolated from E. helioscopia is euphornin (Figure 1). This compound has been demonstrated to inhibit proliferation in vitro of mice lung adenocarcinoma cells (LA795). ${ }^{14}$ However, its potential to act against cervical adenocarcinoma cells has not been investigated to date. Hence, the aims of this study were to evaluate the effect of euphornin treatment on various aspects of proliferation of human cervical adenocarcinoma HeLa cells and to investigate potential molecular mechanisms.

\section{Materials and methods}

\section{Chemicals and reagents}

Euphornin was kindly gifted by Dr Xiao-fei Wang (Lanzhou University, Lanzhou, China) and was dissolved in concentrated dimethyl sulfoxide (DMSO); the stock solution was diluted with phosphate-buffered saline (PBS) to the working concentration before application to cells. The Roswell Park Memorial Institute (RPMI)-1640 medium and fetal calf serum were obtained from Thermo Fisher Scientific (Waltham, MA, USA); Hoechst 33342 and JC-1 dye were purchased from Qianchen Biotechnology Company (Shanghai, China). The Apoptosis Detection Kit (Annexin V-fluorescein isothiocyanate [FITC]/propidium iodide [PI]) was supplied by BD Biosciences (San Jose, CA, USA); the ECL Western Blotting Substrate Kit was obtained from Abnova (Taipei, Taiwan). Rabbit antibodies against cleaved caspase-3, caspase- 8 , caspase- 9 , and caspase- 10 and antibodies against Phospho-CDK1 (Tyr15), CDK1, cytochrome complex (Cyt-C), Bax, Bcl-2, and $\beta$-actin were supplied by Cell Signaling Technology (Beverly, MA, USA).

\section{Cell culture}

The human cervical cancer cell line HeLa and the human fetal lung fibroblast cell line MRC-5 were obtained from the Shanghai Cell Bank of Chinese Academy of Sciences. Cells were grown in the RPMI-1640 medium. Culture media were supplemented with $10 \%$ fetal bovine serum and antibiotics (100 U/mL penicillin and $100 \mathrm{U} / \mathrm{mL}$ streptomycin) and maintained at $37^{\circ} \mathrm{C}$ in a humidified atmosphere and $5 \% \mathrm{CO}_{2}$. The cells were detached using $0.1 \%$ trypsin before use in the experiments.

\section{Cell viability}

The sulforhodamine B (SRB) assay was used to study the effect of euphornin on the proliferation of HeLa and MRC-5 cells. Briefly, cells in logarithmic growth phase were plated into a 96 -well plate at a density of $1.0 \times 10^{4} /$ well. After $24 \mathrm{~h}$ of attachment, the cells were treated with euphornin (50, 100 , and $200 \mathrm{mg} / \mathrm{L}$ ) or vehicle control and incubated for 24 , 48 , or $72 \mathrm{~h}$. The cells were then incubated with $50 \mu \mathrm{L}$ of $10 \%(\mathrm{w} / \mathrm{v})$ trichloroacetic acid at $4^{\circ} \mathrm{C}$ for $1 \mathrm{~h}$, and after five washes, they were stained with $50 \mu \mathrm{L}$ of $0.4 \%(w / v)$ SRB diluted in $1 \%$ acetic acid. Unbound dye was removed with $1 \%$ acetic acid. Protein-bound SRB was solubilized using $200 \mu \mathrm{L}$ of $10 \mathrm{mM}$ Tris base solution, and absorbance was read at $540 \mathrm{~nm}$ wavelength. The experiments were performed using triplicate wells and repeated at least three times. Data were calculated as a percentage of the corresponding control (the untreated control was considered to be $100 \%$ ).

\section{Apoptosis assay}

To determine whether cell death induced by euphornin has apoptotic or necrotic features, Annexin V/PI double staining 
was applied. Briefly, cells were grown in six-well plates and treated with euphornin $(50,100$, and $200 \mathrm{mg} / \mathrm{L})$ for $48 \mathrm{~h}$. The cells were then washed in ice-cold PBS, centrifuged at $1,000 \times g$ for $5 \mathrm{~min}$, resuspended in $500 \mu \mathrm{L}$ binding buffer, and incubated with $5 \mu \mathrm{L}$ Annexin V-FITC and $5 \mu \mathrm{L}$ PI. After 10 min incubation in the dark, cells were assessed on a BD FACSCalibur flow cytometer.

\section{Cell morphology studies}

Morphological changes to cell nuclei were identified after Hoechst 33342 staining. Cells were grown in six-well plates and treated with euphornin $(50,100$, and $200 \mathrm{mg} / \mathrm{L})$ for $48 \mathrm{~h}$. The cells were detached using $0.1 \%$ trypsin and resuspended in the culture medium; they were then incubated with $10 \mu \mathrm{L}$ of Hoechst 33342 dye at $37^{\circ} \mathrm{C}$ for $10 \mathrm{~min}$. After incubation, cells were centrifuged at 1,000 rpm for $5 \mathrm{~min}$, washed, and resuspended in buffer A. They were then analyzed by fluorescence microscopy. Blue fluorescence intensity was measured using a $352 \mathrm{~nm}$ excitation wavelength and $460 \mathrm{~nm}$ emission wavelength.

\section{Mitochondrial membrane depolarization (MMP) analysis using JC-I dye}

The effect of euphornin on MMP was analyzed after staining with JC-1 dye. In healthy mitochondria, JC-1 polymers generate red fluorescence in the mitochondrial matrix. In damaged mitochondria, JC-1 dye accumulates in the cytosol as monomers and generates green fluorescence. HeLa cells were treated with euphornin for $48 \mathrm{~h}$. Control cultures were treated with the same amount of the vehicle. Cells were incubated with $10 \mathrm{mg} / \mathrm{mL} \mathrm{JC}-1$ dye for $20 \mathrm{~min}$ at $37^{\circ} \mathrm{C}$ and washed in PBS followed by centrifugation in accordance with the manufacturer's protocol. Cells were immediately analyzed using flow cytometry. The ratio of red to green fluorescence was used to monitor changes in MMP.

\section{Cell cycle assay}

Fluorescence-activated cell sorting was applied to investigate the influence of euphornin on cell cycles. Cells treated with or without euphornin were maintained in culture for $48 \mathrm{~h}$. They were then collected and washed in precooled PBS, centrifuged at $1,000 \times g$ for $5 \mathrm{~min}$, and fixed in $70 \%$ ethanol at $4{ }^{\circ} \mathrm{C}$ overnight. The cells were washed in PBS and incubated with RNase and PI (final concentration: $50 \mu \mathrm{g} / \mathrm{mL}$ ) for $30 \mathrm{~min}$ in the dark. The results were analyzed using FlowJo 7.6.1 Min software. Assays were performed on three separate occasions.

\section{Western blot assay}

The culture medium was discarded, and the cells were washed twice in ice-cold PBS; they were then lysed in freshly prepared radioimmunoprecipitation assay (RIPA) buffer containing protease inhibitors and phosphatase inhibitors. The culture plates were incubated for $30 \mathrm{~min}$ on ice, and the cells were scraped from the wells and collected in an eppendorf tube; they were centrifuged at $17,000 \times g$ for $15 \mathrm{~min}$. The supernatants were saved as total cellular proteins.

For immunoblotting experiments, concentrations of total cellular proteins were estimated using a BCA Protein Assay Kit. Protein extracts were separated by sodium dodecyl sulfate (SDS)-polyacrylamide gel electrophoresis and then transferred onto a polyvinylidene difluoride (PVDF) membrane. The membranes were blocked with $5 \%$ milk or bovine serum albumin in Tris-buffered saline and then blotted with primary antibodies overnight at $4^{\circ} \mathrm{C}$. After washing, the membranes were incubated with horseradish peroxidase-conjugated secondary antibody for $2 \mathrm{~h}$ at room temperature. Proteins were detected using an ECL Western Blotting Substrate Kit. The antibody concentrations used here were phospho-CDK1 (Tyr15), 1:1,000; total CDK1, 1:1,000; Cyt-C, 1:1,500; Bcl-2, 1:1,500; Bax, 1:1,500; and caspase-3, caspase-8, caspase-9, caspase-10, and $\beta$-actin, 1:3,000. The total protein content was normalized using mouse anti- $\beta$-actin antibody. Densitometric analysis of immunoreactivity for each protein was performed using Image-Pro Plus 6.0 software (Media Cybernetics, Rockville, MD, USA).

\section{Statistical analysis}

Data are expressed as mean \pm SD from three individual experiments. Analysis of variance (ANOVA) and post-hoc Tukey's tests were performed for all experiments. Probability values were considered as statistically significant at $P<0.05$.

\section{Results}

\section{Euphornin inhibits HeLa cell proliferation}

Dose- and time-dependent changes in HeLa cell viability were determined using the SRB assay after incubation periods of 24,48 , and 72 h. As shown in Figure 2A, treatment with euphornin induced dose- and time-dependent changes in cell viability. After treatment with $50 \mathrm{mg} / \mathrm{L}$, cell viability was $89.9 \%$ of that in vehicle-treated control cells and was further reduced at 100 and $200 \mathrm{mg} / \mathrm{L}$ dosages. In a similar manner, cell viability decreased with the duration of euphornin treatment. The effects of euphornin on the non-tumoral cell 
A

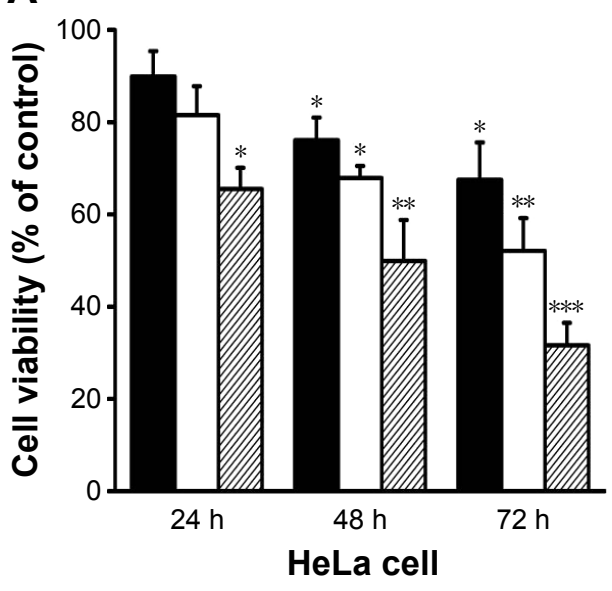

B

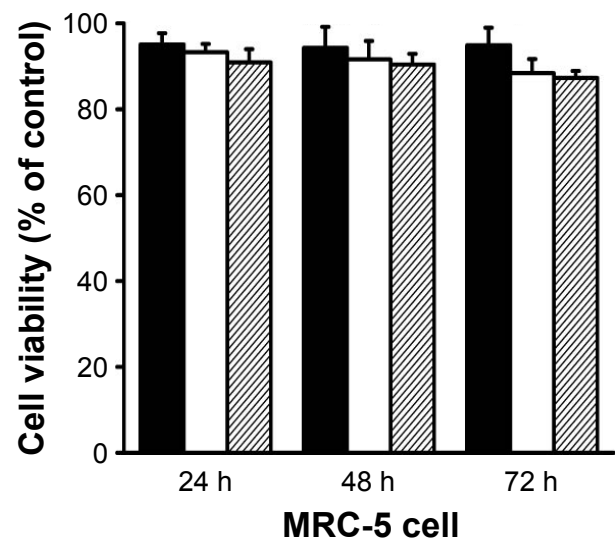

Euphornin 50 mg/L $\square$ Euphornin 100 mg/L Euphornin 200 mg/L

Figure 2 Effects of euphornin on HeLa and MRC-5 cell viability.

Notes: Changes in rates of viability of HeLa (A) and MRC-5 (B) cell lines after 24, 48, and $72 \mathrm{~h}$ treatment with 50, 100 , or 200 mg/L euphornin. Cell viability was determined by an SRB assay. ${ }^{*} P<0.05$, ${ }^{* * P}<0.01$, and ${ }^{* * * P}<0.001$ vs control.

Abbreviation: SRB, sulforhodamine $B$.

line MRC-5 were also tested; no significant effect of dose or time was found for MRC-5 cell viability (Figure 2B).

\section{Euphornin induces HeLa cell apoptosis}

The rate of apoptosis was measured by Annexin V/PI double staining. Over the tested dose range, the rate of apoptosis increased from $25.3 \%$ to $52.6 \%$ (Figure 3 ); a dose-dependent increase in apoptosis was identified.

\section{Euphornin induces cell morphology changes in HeLa cells}

Next, we used Hoechst 33342 staining to examine the morphology of HeLa cells after euphornin treatment. As shown in Figure 4, treatment with 50-200 mg/L euphornin for $48 \mathrm{~h}$ induced clear changes in cell structure and density and induced DNA fragmentation and/or chromatin condensation.

\section{Euphornin induces MMP loss in HeLa cells}

The collapse of MMP is an essential event in the mitochondrial pathway of apoptosis. As shown in Figure 5, the red to green fluorescence ratio decreased in cells treated with euphornin. The obtained results indicated that euphornin decreased the number of cells with normal membrane potential and increased the number of cells with low MMP after $48 \mathrm{~h}$.

\section{Euphornin activates the mitochondrial pathway in HeLa cells}

The mitochondrial Bcl-2 gene family contains some important apoptotic regulators, such as Bcl-2 and Bax, which participate in the process of cell death. After treatment with euphornin, the level of Bcl-2 protein in HeLa cells fell while that of Bax increased gradually. The ratio between antiapoptotic (Bcl-2) and proapoptotic (Bax) Bcl-2 family proteins was reduced in euphornin-treated cells in a dose-dependent manner (Figure 6A). Based on these data, we propose that an intrinsic mitochondrial pathway may be involved in euphornin-induced apoptosis.

\section{Euphornin induces apoptosis via caspase- mediated pathways in HeLa cells}

To determine whether the Cyt-C or caspase-mediated pathway also participated in euphornin-induced apoptosis in $\mathrm{HeLa}$ cells, the levels of Cyt-C, caspase-3, caspase-8, caspase-9, and caspase- 10 were determined by Western blot analyses. The level of Cyt-C was increased in euphornin-treated HeLa cells (Figure 6B). Likewise, the levels of caspase-3, caspase-8, caspase-9, and caspase-10 in euphornin-treated HeLa cells increased in a dose-dependent manner (Figure 6C). These results suggest that euphornin induced apoptosis via caspasemediated pathways in HeLa cells.

\section{Euphornin treatment arrests cell cycle progression in HeLa cells}

The flow cytometric analysis of euphornin-treated HeLa cells showed an altered cell cycle pattern (Figure 7). Compared to the control group, the number of cells at $\mathrm{G} 2 / \mathrm{M}$ increased in a dose-dependent manner. Cell numbers at G0/G1 or $\mathrm{S}$ phases did not display any obvious trend. 
A

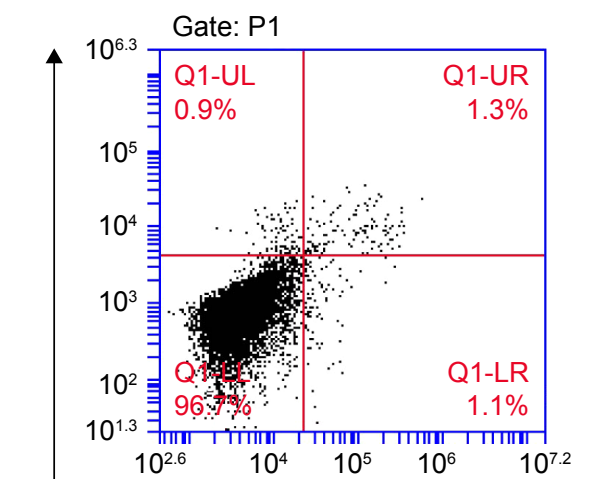

$\bar{\alpha}$

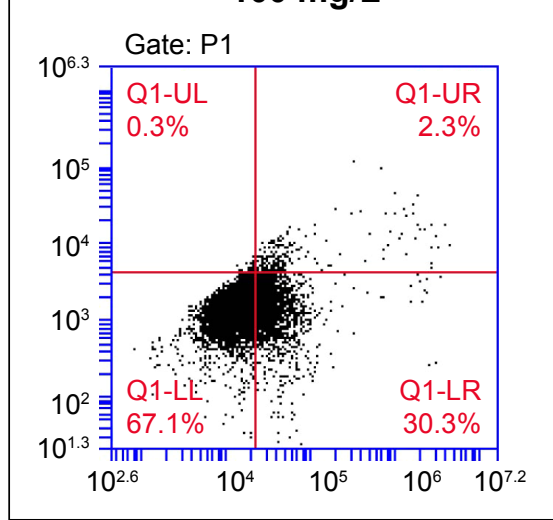

$50 \mathrm{mg} / \mathrm{L}$

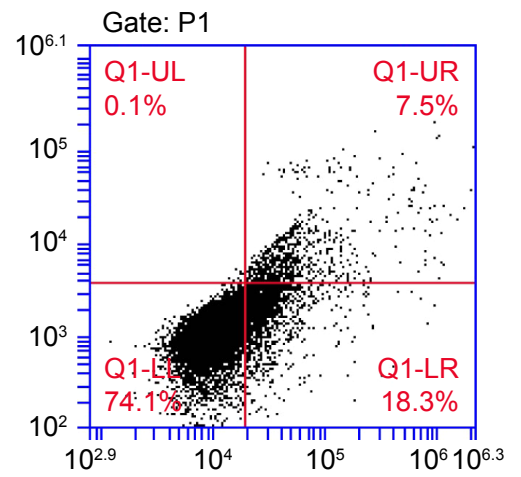

$200 \mathrm{mg} / \mathrm{L}$

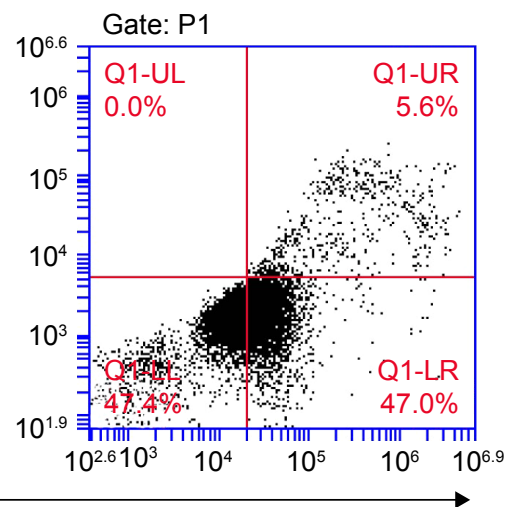

B

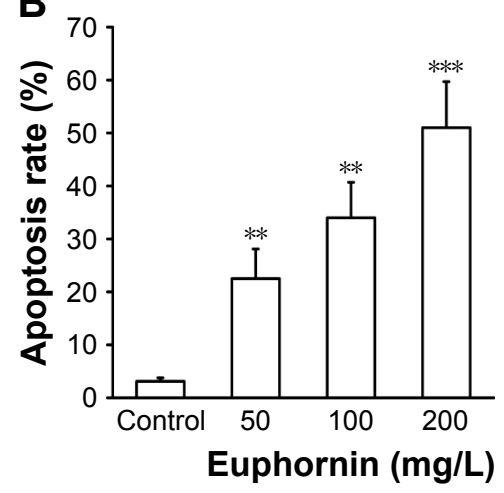

Annexin V

Figure 3 Effect of euphornin on the rate of apoptosis in HeLa cells.

Notes: (A) Flow cytometric analysis of HeLa cells treated with PBS, 50, 100, or $200 \mathrm{mg} / \mathrm{L}$ euphornin for 48 h. Representative dot plots of cell apoptosis are shown after Annexin V/PI dual staining. (B) Rate of apoptosis is represented as the percentage of the total cell population. The proportions of dead cells (UL: Annexin V-/PI+), live cells (LL: Annexin V-/PI-), early apoptotic cells (LR: Annexin $\mathrm{V}+/ \mathrm{PI}-$ ), and late apoptotic/necrotic cells (UR: Annexin $\mathrm{V}+/ \mathrm{PI}+$ ) were measured for comparison. $* * P<0.0 \mathrm{I}$ and $* * * P<0.00$ I vs control.

Abbreviations: LL, lower left; LR, lower right; PBS, phosphate-buffered saline; PI, propidium iodide; UL, upper left; UR, upper right.

As orderly cell cycle transition is associated with the activation of phase-specific cyclin-dependent kinases (CDKs), we examined the effect of euphornin treatment on the level of phospho-CDK1 (Tyr15). Our analysis showed a dosedependent change in phospho-CDK1 (Tyr15), whereas the total CDK1 level showed no change.

\section{Discussion}

In this study, we demonstrated that euphornin inhibited proliferation of human cervical cancer HeLa cells over a concentration range of $50-200 \mathrm{mg} / \mathrm{mL}$ in a concentration- and time-dependent manner. Annexin V/PI and Hoechst staining demonstrated that the cell proliferation blocking effect was mediated by an increased rate of apoptosis in HeLa cells. A loss of MMP and cell cycle arrest at G2/M were observed in the euphornin-treated HeLa cells. Induced apoptosis in HeLa cells appeared to be mediated, in part at least, by mitochondrial and caspase pathways. Our findings suggested that euphornin suppressed proliferation of human cervical cancer HeLa cells and suggested that this compound might have potential value for pharmacotherapeutic treatment of human cervical cancer.

Many studies in recent years have reported an association between antiapoptotic molecules and therapeutic targets for cancer treatment. ${ }^{15,16}$ In view of the importance of apoptotic cell death as a key mechanistic feature of potential antitumor drugs, we investigated the potential application of euphornin to induce apoptosis. The occurrence of apoptosis is associated with classic morphological and biochemical changes in cells. ${ }^{6,17}$ In the present study, morphological changes were identified after treating HeLa cells with euphornin. Euphornin significantly increased the rate of apoptosis in HeLa cells. A previous study indicated that the loss of MMP occurs during cell apoptosis; this loss is followed by the release of proapoptotic molecules and Cyt-C. ${ }^{18}$ Here, we showed that euphornin treatment resulted in an increase in cytoplasmic Cyt- $\mathrm{C}$ and a decrease in MMP. In addition, euphornin-treated HeLa cells showed an altered Bax/Bcl-2 ratio, demonstrating 

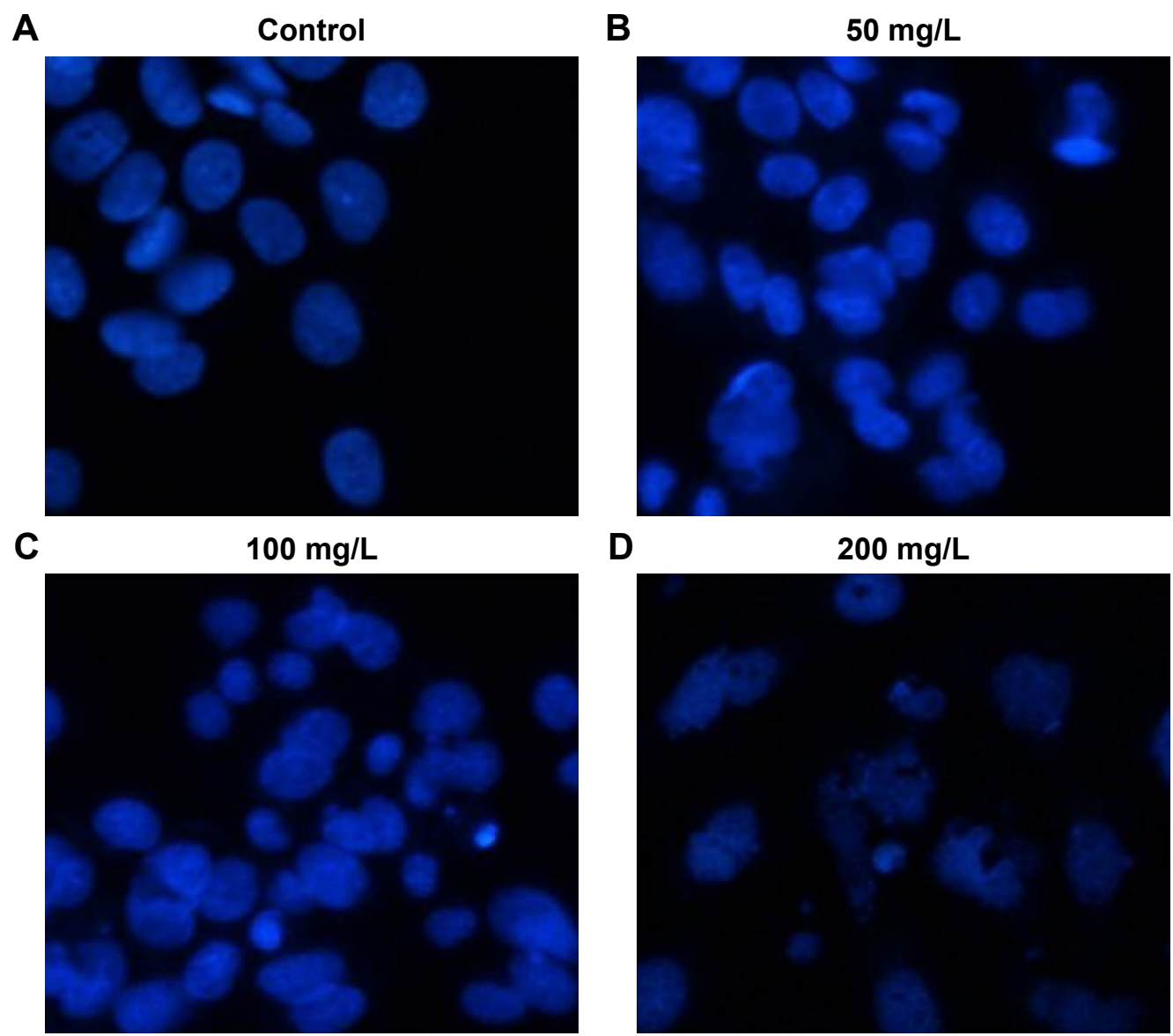

Figure 4 Morphological changes in apoptotic HeLa cells.

Notes: Following treatment with (A) PBS, (B) 50, (C) 100, or (D) $200 \mathrm{mg} / \mathrm{L}$ euphornin for $48 \mathrm{~h}$, apoptotic nuclei were identified as condensed and brightly stained with Hoechst 33342. Nuclear morphology was visualized under a fluorescence microscope $(\times 200)$ and photographed.

Abbreviation: PBS, phosphate-buffered saline.

that euphornin influenced mitochondrial membrane stability. It has previously been shown that alteration of the Bax/Bcl-2 ratio can play an important role in regulating cellular apoptotic processes and flipping the Bax/Bcl-2 switch to kill cancer cells..$^{19,20}$
Caspases, protease enzymes, are also critical in the initiation of apoptosis and are activated in cells undergoing apoptosis. ${ }^{21}$ The activation of caspase- 3 is considered as a robust signal of apoptosis. ${ }^{22}$ Here, we found that cleaved caspase-3 levels were significantly enhanced after euphornin treatment,
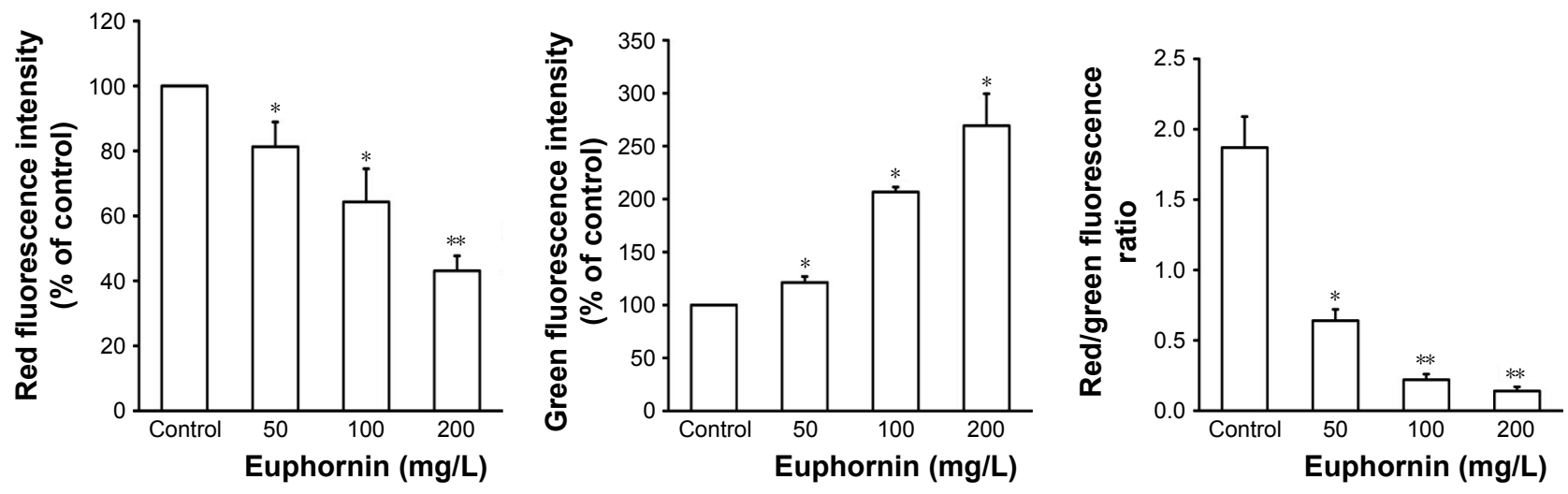

Figure 5 Effect of euphornin on MMP in HeLa cells.

Notes: HeLa cells were treated with PBS, 50, 100, or $200 \mathrm{mg} / \mathrm{L}$ euphornin for $48 \mathrm{~h}$. MMP was assessed after staining with JC-I dye. Qualitative analysis of changes in MMP was examined by quantification of the ratio of red and green fluorescence. $* P<0.05$ and $* * P<0.01$ vs control.

Abbreviations: MMP, mitochondrial membrane depolarization; PBS, phosphate-buffered saline. 
thus promoting apoptotic progress. The increase in levels of caspases plays a vital role in the apoptotic signaling interactions that are activated in most instances of apoptotic cell death. ${ }^{23}$ To identify the apoptotic pathway activated by euphornin,

$\mathbf{A}$
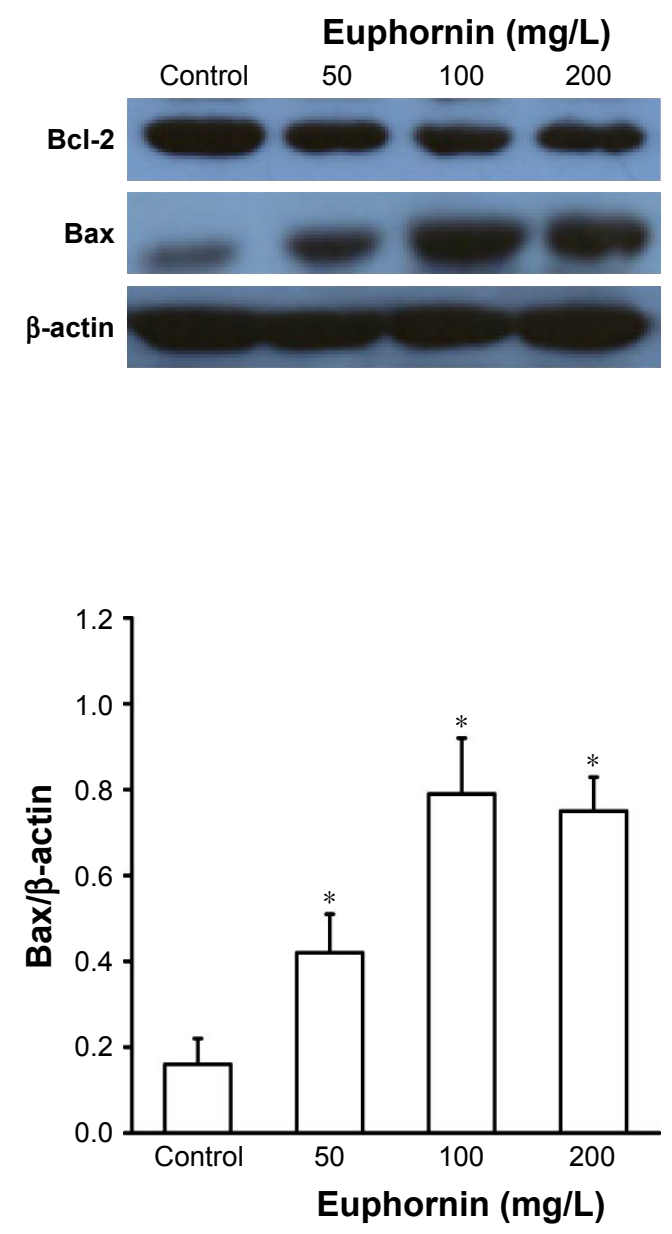

B

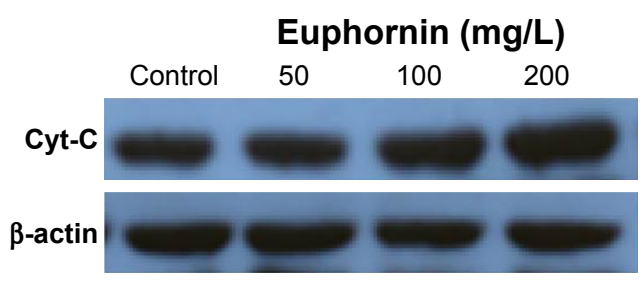

we evaluated the levels of caspase- 8 , caspase- 9 , and caspase-10 apical proteases in extrinsic and intrinsic pathways. Our assay revealed that the levels of caspase proteins increased in a dosedependent manner after euphornin treatment and confirmed
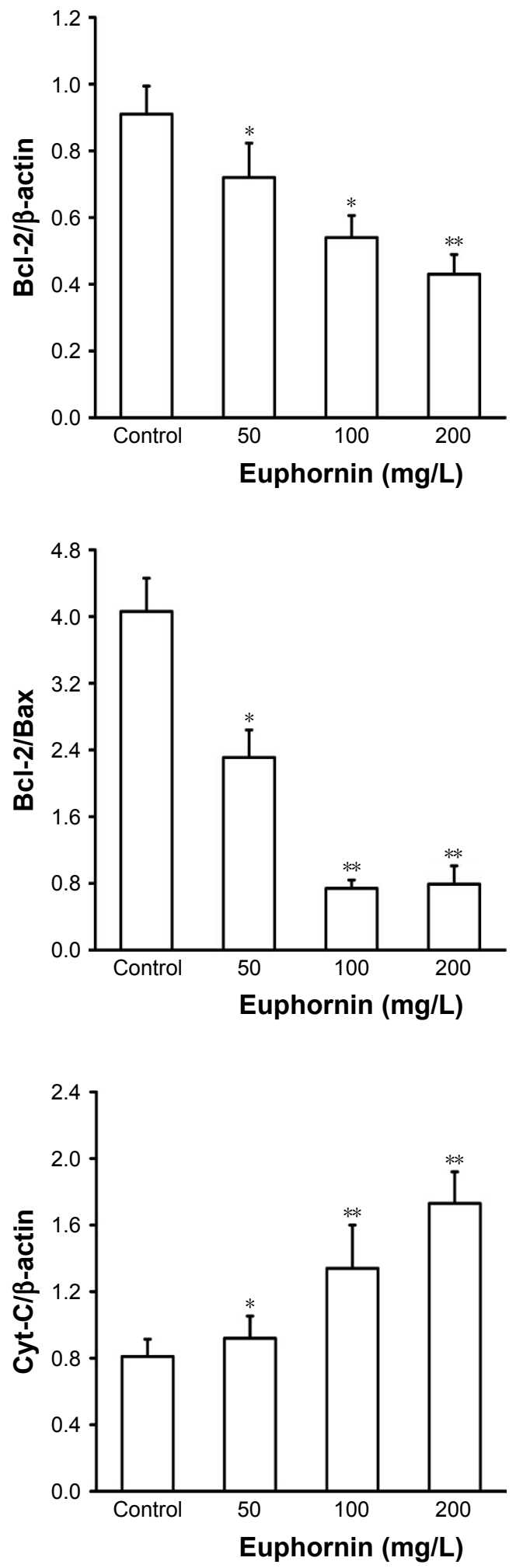

Figure 6 (Continued) 
C
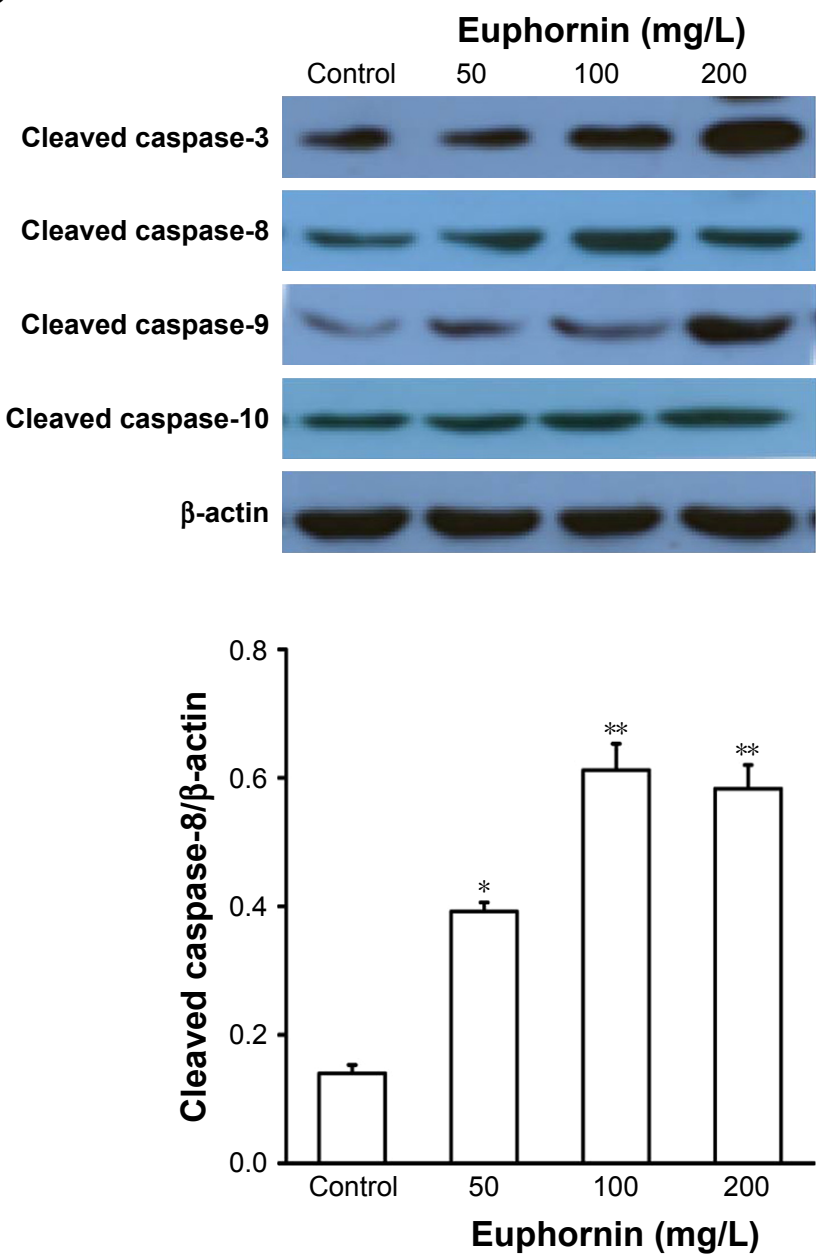
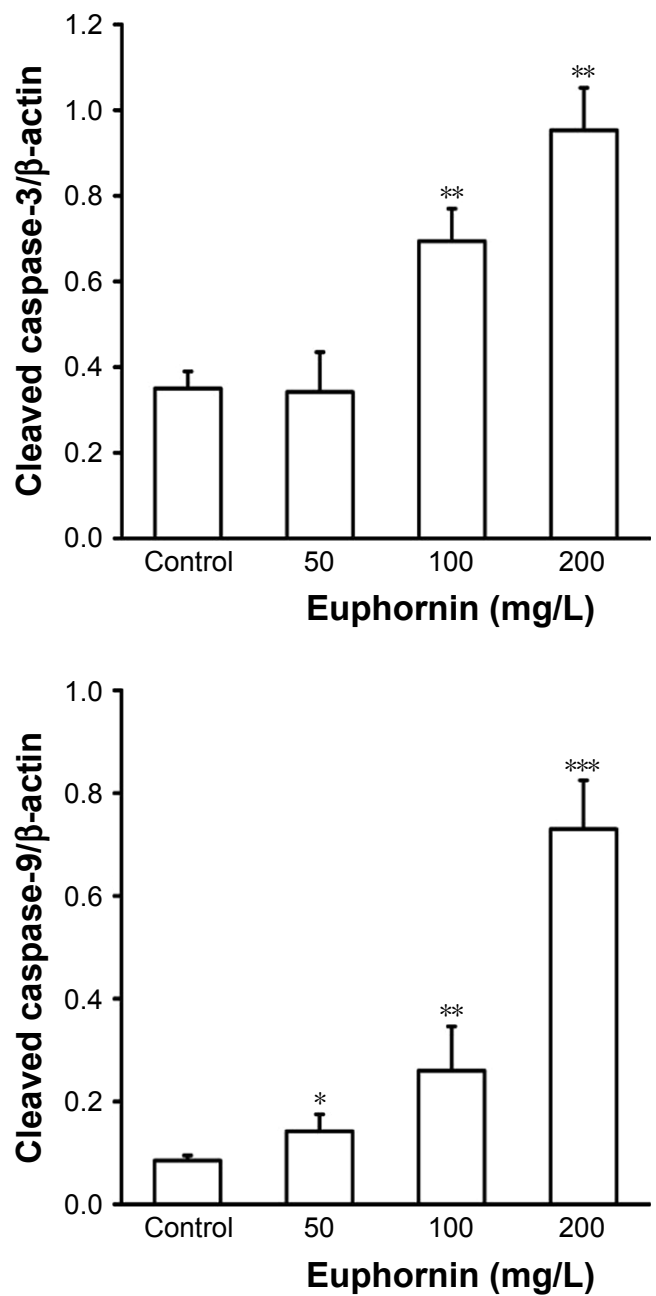

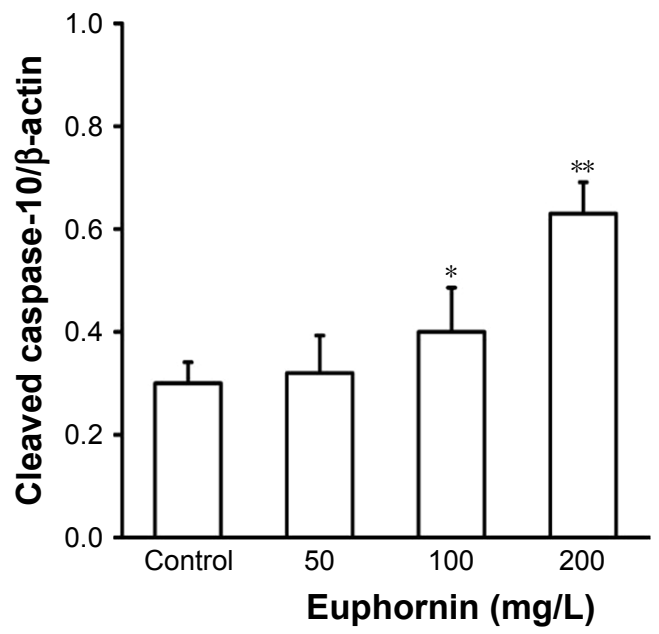

Figure 6 Effects of euphornin on apoptotic proteins in HeLa cells.

Notes: HeLa cells were treated with PBS, 50, 100, or $200 \mathrm{mg} / \mathrm{L}$ euphornin for $48 \mathrm{~h}$. Western blot analysis was used to determine the protein expression levels. $* P<0.05$, $* * \mathrm{P}<0.0 \mathrm{I}$, and $* * * \mathrm{P}<0.00 \mathrm{I}$ vs control. (A) Expression of bcl-2 and bax; (B) expression of Cyt-C; (C) expression of caspase-3, caspase-8, caspase-9, and caspase-10. Abbreviation: PBS, phosphate-buffered saline.

that caspase-3, caspase-8, caspase-9, and caspase-10 played a role in euphornin-induced apoptosis in HeLa cells.

Deregulation of cell cycle progression is a common characteristic of cancer cells ${ }^{24}$ and regulates the rate of cell proliferation. Regulation of cell cycle arrest at G2/M is a feature of interest in studies on cell proliferation in basic and clinical cancer studies. ${ }^{25}$ Our analyses here demonstrated that euphornin increased the rate of cells at G2/M and, therefore, 


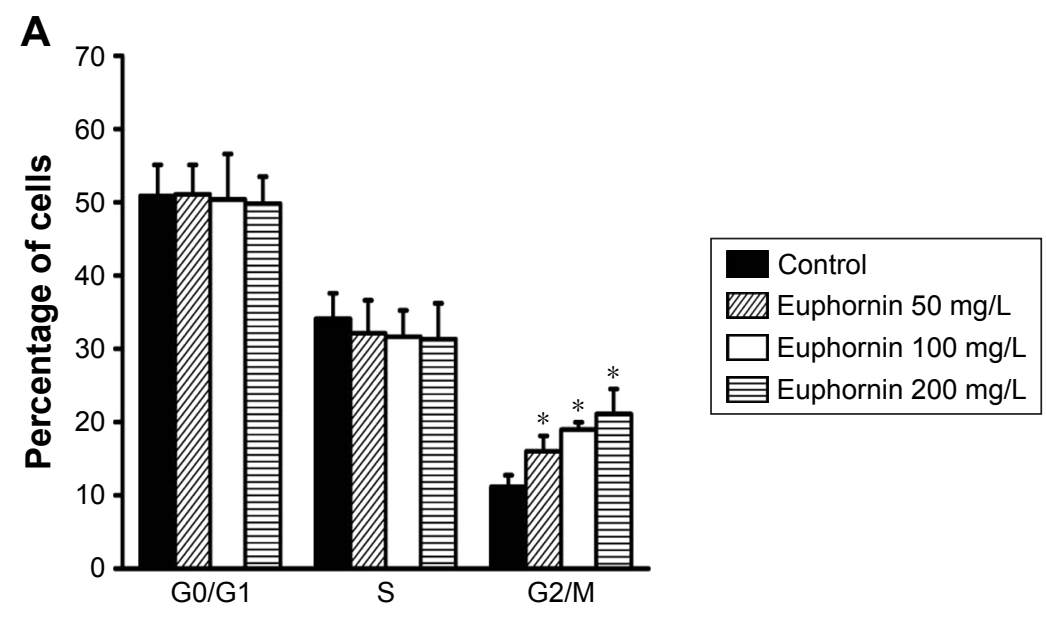

B
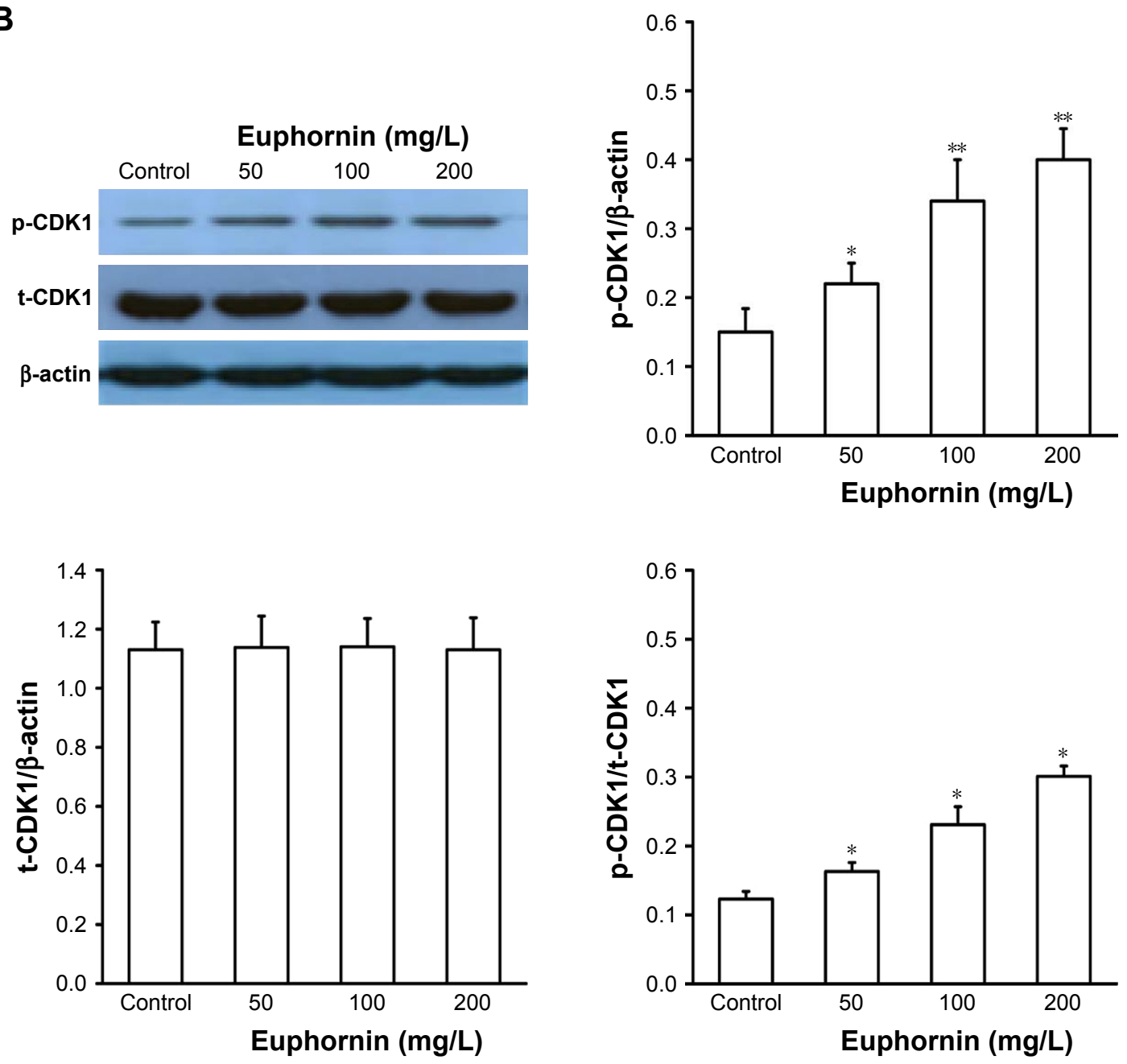

Figure 7 Effect of euphornin on cell cycle progression in HeLa cells.

Notes: HeLa cells were treated with PBS, 50, 100, or $200 \mathrm{mg} / \mathrm{L}$ euphornin for $48 \mathrm{~h}$. (A) Cells fixed and stained with PI for flow cytometric analysis of DNA content and cell cycle distribution. (B) Cell cycle-associated protein expression (CDKI) was detected by Western blot. $* P<0.05$ and $* * P<0.0 \mathrm{I}$ vs control.

Abbreviations: PBS, phosphate-buffered saline; PI, propidium iodide.

had a significant effect on cell cycle progression compared with cultures treated with the vehicle control; these observations indicate the potential of euphornin to regulate the $\mathrm{G} 2 / \mathrm{M}$ phase.
The cell cycle is driven by proteins called CDKs that associate with cyclin regulatory proteins at different points of the cell cycle. CDK1-cyclin B complex plays a key role in G2/M-phase transition. Proteins that localize to sites of 
DNA damage in G2 initiate a signaling cascade that regulates CDK1-cyclin B complex activity, therefore controlling mitotic entry. ${ }^{26} \mathrm{CDK} 1$, also known as cell division cycle protein 2 (cdc2), is a highly conserved protein that functions as a serine/threonine kinase. Activation of CDK1 is an important regulatory step in controlling mitotic entry via CDK1-cyclin B complex. CDK1 activity is regulated by phosphorylation of its tyrosine-15 residue. Phosphorylation of tyrosine-15 inhibits CDK1 activity, while dephosphorylation removes negative regulation of CDK 1 activity and causes cells to enter mitosis and therefore hyphosphorylation of tyrosine-15 residue and reduced activity of CDK1 associated with G2/M cell cycle arrest. ${ }^{27,28}$ Here, we showed that euphornin treatment increased the level of phospho-cdk1 (Tyr15) protein and led to deactivation of the CDK1-cylinB complex; this deactivation prevented the transition from G2 to M phase, induced abnormal cell cycle regulation, and subsequently inhibited cell proliferation. These observations suggest that CDK1 is involved in the euphornin-induced cell cycle arrest in HeLa cells.

\section{Conclusion}

We demonstrated that euphornin, isolated from the plant E. helioscopia, inhibits proliferation of cervical cancer HeLa cells in a concentration- and time-dependent manner. Moreover, euphornin induced apoptosis and G2/M-phase cell cycle arrest and altered the levels of cell cycle-dependent kinases. Euphornin induced HeLa cell apoptosis through both mitochondrial and caspase pathways. Taken together, our data suggest that euphornin has both antiproliferation and proapoptotic properties in cervical cancer HeLa cells. Further studies will be required to identify the specific molecular targets of euphornin and the signaling pathways affected in vivo.

\section{Acknowledgment}

This study was supported by the Natural Science Foundation of Gansu Province, China (Grant No: 1506RJZA251).

\section{Author contributions}

All authors contributed toward data analysis, drafting, and critically revising the paper and agree to be accountable for all aspects of the work.

\section{Disclosure}

The authors report no conflicts of interest in this work.

\section{References}

1. Waggoner SE. Cervical cancer. Lancet. 2003;361(9376):2217-2225.

2. Kim MK, Kim HS, Kim SH, et al. Human papillomavirus type 16 E5 oncoprotein as a new target for cervical cancer treatment. Biochem Pharmacol. 2010;80(12):1930-1935.
3. Villa LL. Human papillomaviruses and cervical cancer. Adv Cancer Res. 1997;71:321-341.

4. Rose PG. Chemoradiotherapy for cervical cancer. Eur J Cancer. 2002; 38(2):270-278.

5. Iida M, Banno K, Yanokura M, et al. Candidate biomarkers for cervical cancer treatment: potential for clinical practice. Mol Clin Oncol. 2014; 2(5):647-655

6. Hengartner MO. The biochemistry of apoptosis. Nature. 2000;407(6805): 770-776.

7. Thompson CB. Apoptosis in the pathogenesis and treatment of disease. Science. 1995;267(5203):1456-1462.

8. Chandra P. Molecular approaches for designing antiviral and antitumor compounds. Top Curr Chem. 1974;52:99-139.

9. Min LW. Targeting apoptosis pathways in cancer by Chinese medicine. Cancer Lett. 2013;332(2):304-312.

10. Thomas E, Li PCH, Konkimalla VSB, Bernd K. From traditional Chinese medicine to rational cancer therapy. Trends Mol Med. 2007; 13(8):353-361.

11. Ghen Y, Tang ZJ, Jiang FX, Zhang XX, Lao AN. Studies on the active principles of Ze-Qi (Euphorbia helioscopia L.), a drug used for chronic bronchitis (I). Yao Хие Хие Вao. 1979;14(2):91-95.

12. Uzair M, Loothar BA, Choudhary BA. Biological screening of Euphorbia helioscopia L. Pak J Pharm Sci. 2009;22(2):184-186.

13. Wang ZY, Liu HP, Zhang YC, Guo LQ, Li ZX, Shi XF. Anticancer potential of Euphorbia helioscopia L extracts against human cancer cells. Anat Rec. 2012;295(2):223-233.

14. Haixia C, Zhao SW, Li Y. Analysis of euphornin in Euphorbia helioscopia $\mathrm{L}$. and its cytotoxicity to mice lung adenocarcinoma cells (LA795). Nat Prod Res. 2012;26(22):2112-2116.

15. Fernald K, Kurokawa M. Evading apoptosis in cancer. Trends Cell Biol. 2013;23(12):620-633.

16. Michele $\mathrm{S}$, Lucia RV, Ruggero DM. Targeting apoptosis pathways in cancer stem cells. Cancer Lett. 2013;332(2):374-382.

17. Green DR, Reed JC. Mitochondria and apoptosis. Science. 1998; 281(5381):1309-1312.

18. Xue WU, Chen YH, Jiang CY, et al. Effect of PBDE-47 on apoptosis, mitochondrial membrane potential and protein expression of cytochrome C in SHSYSY cells. J Environ Health. 2012;29(8):675-678.

19. Bagci EZ, Vodovotz Y, Billiar TR, Ermentrout GB, Bahar I. Bistability in apoptosis: roles of Bax, Bcl-2, and mitochondrial permeability transition pores. Biophys J. 2006;90(5):1546-1559.

20. Cory S, Adams JM. Killing cancer cells by flipping the Bcl-2/Bax switch. Cancer Cell. 2005;8(1):5-6.

21. Fan TJ, Han LH, Cong RS, Liang J. Caspase family proteases and apoptosis. Acta Biochim Biophys Sin (Shanghai). 2005;37(11):719-727.

22. Porter AG, Jänicke RU. Emerging roles of caspase-3 in apoptosis. Cell Death Differ. 1999;6(2):99-104.

23. Winter E, Chiaradia LD, Silva AH, Nunes RJ, Yunes RA, Creczynski-Pasa TB. Involvement of extrinsic and intrinsic apoptotic pathways together with endoplasmic reticulum stress in cell death induced by naphthylchalcones in a leukemic cell line: advantages of multi-target action. Toxicol In Vitro. 2014;28(5):769-777.

24. Evan GI, Vousden KH. Proliferation, cell cycle and apoptosis in cancer. Nature. 2001;411(6835):342-348.

25. Löbrich M, Jeggo PA. The impact of a negligent G2/M checkpoint on genomic instability and cancer induction. Nat Rev Cancer. 2007; 7(11):861-869.

26. John PCL, Mews M, Moore R. Cyclin/cdk complexes: their involvement in cell cycle progression and mitotic division. Protoplasma. 2001; 216(3-4):119-142.

27. Tyagi A, Agarwal C, Harrison G, Glode LM, Agarwal R. Silibinin causes cell cycle arrest and apoptosis in human bladder transitional cell carcinoma cells by regulating CDKI-CDK-cyclin cascade, and caspase 3 and PARP cleavages. Carcinogenesis. 2004;25(9):1711-1720.

28. O'Connell MJ, Raleigh JM, Verkade HM, Nurse P. Chk1 is a wee1 kinase in the g2 DNA damage checkpoint inhibiting cdc2 by Y15 phosphorylation. EMBO J. 1997;16(3):545-554. 
OncoTargets and Therapy

\section{Publish your work in this journal}

OncoTargets and Therapy is an international, peer-reviewed, open access journal focusing on the pathological basis of all cancers, potential targets for therapy and treatment protocols employed to improve the management of cancer patients. The journal also focuses on the impact of management programs and new therapeutic agents and protocols on

patient perspectives such as quality of life, adherence and satisfaction. The manuscript management system is completely online and includes a very quick and fair peer-review system, which is all easy to use. Visit http://www.dovepress.com/testimonials.php to read real quotes from published authors.

Submit your manuscript here: http://www.dovepress.com/oncotargets-and-therapy-journal 